This is a self-archived version of an original article. This version may differ from the original in pagination and typographic details.

Author(s): Tuikka, Sini

Title: Negative Relationships in the Workplace

Year: 2020

Version: Accepted version (Final draft)

Copyright: (c) 2020 Taylor \& Francis

Rights: In Copyright

Rights url: http://rightsstatements.org/page//nC/1.0/?language=en

Please cite the original version:

Tuikka, S. (2020). Negative Relationships in the Workplace. In L. Mikkola, \& M. Valo (Eds.), Workplace Communication (pp. 136-148). Routledge. https://doi.org/10.4324/978042919688111 


\title{
11 Negative Relationships in the Workplace
}

\author{
Sini Tuikka 0000-0003-3858-418X
}

\begin{abstract}
A workplace is a network of various relationships, each with their own distinctive features. Negative coworker relationships, such as bullying relationships, may cause significant long-term emotional and psychophysical strain for the individuals involved, the coworkers who observe such relationships, and the entire organization. In contrast to an isolated workplace conflict, a negative relationship can include recurring patterns of dismissive and offensive communication or the perceived threat of such. This chapter explores nonvoluntary relationships that the participants are, to a certain extent, forced to maintain due to their shared office space and organizational goals. Because ending these relationships is not an option in the foreseeable future, the chapter discusses their maintenance. Ways of initiating discussions of relational problems are also discussed.
\end{abstract}

\section{Introduction}

Many people spend more time with their coworkers than with the people to whom they are closest. Functional coworker relationships are closely connected to individual well-being and the perceived quality of (working) life. They are a valuable job resource and can support the success of organizations through, for example, enhanced worker motivation, trust, engagement, and commitment as well as decreased turnover intentions (e.g., Chiaburu \& Harrison 2008).

A workplace is a network of various relationships, each with distinctive features. Although coworker relationships are primarily task-oriented, they can be described in more detail based on the quality of the communication that characterizes them. Based on the time people spend together, the conversation topics, and the perceived closeness, some coworker relationships are similar to friendships. At the same time, many of these relationships are simply neutral, even somewhat insignificant (Methot, Melwani, \& Rothman 2017). However, we also know that coworker relationships can cause significant long-term emotional and psychophysical strain. A relationship of this kind is far from neutral and insignificant, even though it might appear to be.

Isolated hurtful incidents are unavoidable in any relationship. Yet, in a negative and hostile relationship, the feeling of being hurt is a more permanent and distinctive feature (Keashly \& Jagatic 2003). Negative relationships can last a long time, even though they do not embody the positive features that usually reinforce relational continuity. No line of work involving communication is probably immune to the possibility of negative relationship development. Here the terms negative coworker relationships and problematic coworker relationships are used synonymously. 
Negative relationships result in distraction from work and they typically complicate the ways the parties communicate with each other. Problems in coworker relationships can be determinants of depression and other severe health outcomes. They reduce commitment, job satisfaction, and work efficiency. They increase stress and emotional load, employee turnover, and cynicism toward the workplace as well as a negative attitude toward working life in general (Fritz \& Omdahl 2006). The causes can be crippling not only for the people who perceive themselves as targets of negative behaviors or who are accused of performing negative behaviors, but also for the other people who observe them. Negative behaviors and relationships, such as those involving workplace bullying, tend to cause sickness absences, reduced motivation, and decline in work quality. Scholars have estimated their financial consequences are very high (Kline \& Lewis 2019).

Direct confrontations and perceived negative behaviors are often ambiguous; they may not be clearly evident or easily noticeable. Still, simply having to be in close proximity to a person perceived as negative on a daily basis causes long-term emotional strain. By the necessity of maintaining the relationship against one's will, the strain contributes to the overall perception of the relationship's negativity (Rainivaara 2009).

Identifying the communicational features of negative relationships helps us piece together an accurate picture of the different kinds of relationships in organizations. This chapter aims to provide an understanding of negative relationships, their development, and their maintenance. This understanding helps us to identify ways to support the development of less burdensome and even more positive relationships.

\section{Nonvoluntary Relationships}

Often, coworker relationships are long-term relationships. In principle, a negative relationship begins on a coincidental basis; we do not choose or get to know our coworkers before working with them. Nonvoluntary relationships are a universal type of relationship (Hess 2003). The distinctive feature of such relationships is that the participants perceive that they have no other choice than to maintain them, due to various internal and external reasons. These types of relationships are maintained formally. Unlike voluntary relationships, the participants typically do not communicate in ways that indicate mutual liking, emotional closeness, or motivation to actually want to be in the relationship. In the workplace, nonvoluntary relationships can exist when one is working on the same team with someone simply as part of the job requirement and 
in order to accomplish the goals of the work. Without this external factor, coworkers would most likely not spend any additional time together.

Of course, nonvoluntary relationships are not all inherently negative and hurtful. Avoiding nonvoluntary relationships is therefore neither necessary nor possible. Instead, they are just one example of the variety of relationships we encounter, and they are a reminder that we maintain many nonvoluntary relationships in the course of our lives.

Maintaining nonvoluntary relationships in the workplace exhibits some differences from maintaining other types of relationships, such as those with acquaintances (Hess 2002; 2006). In the workplace, there are clear expectations regarding the communication and behavior of professionals. There are rules (written and unwritten) that control the relationships and communication practices between colleagues. Expectations regarding, for example, expressing and managing negative emotions are more explicit in the workplace, because people are expected to carefully control their behavior (Kramer \& Hess 2002).

These expectations partly explain why distancing behaviors are more common in maintaining nonvoluntary workplace relationships than relationships outside the office. Distancing refers to both physical distance and wishing to be relationally separated from a coworker. In the workplace, distancing can be communicated by engaging in predominantly professional, externally polite, and civil interactions and consciously avoiding the expression of the negative emotions that can be caused by the relationship. Furthermore, interactions that are typically oriented toward enhancing relational closeness, such as self-disclosure, can be avoided in workplace settings. Employees even adopt various strategies of avoiding at least any unnecessary interaction with the coworker, if possible (Hess 2006).

Negative and problematic relationships in one's working life are similar to nonvoluntary relationships in the sense that they are also maintained through daily workplace communication and work-related encounters. However, maintaining problematic relationships is far more emotionally demanding than maintaining neutral nonvoluntary relationships.

\section{The Difficulty of "Difficult"}

In the workplace, problematic and negative behaviors can range from an isolated incident and minor (yet sometimes extremely annoying) habits and patterns of negative behaviors to 
excessive, long-term emotional strain. The most problematic relationships are undoubtedly those including uncivil, aggressive, (sexually) harassing, unwanted, or unprofessional conduct by coworkers, leaders, or their followers, and by unresolved and repeated conflicts in these relationships. One can easily describe the characteristics of a difficult, abusive, and/or incompetent boss, but it is essential to remember that followers also possess the ability and means to complicate their leader's work. Repeated aggressive behavior, a style of aggressive conflict, rigidity, low work motivation, and constant resistance to change are a few examples of the ways a staff member can attack and question the leader's status and competence (Branch, Ramsay, \& Barker 2007). Similarly, the leader can perceive such an employee as a difficult follower.

Employees perceived as workplace bullies are also typically characterized as having difficult personalities. The targets of negative behaviors can end up being similarly labeled: A person determined to remediate office flaws, seek justice, and strongly defend themselves against treatment perceived as unfair can also occasionally end up being perceived as "the difficult one" (e.g., Leymann 1996).

Difficult personalities do not exist in a void, that is, an employee is perceived as difficult only when an interaction gives rise to such a perception. Therefore, the behavior of presumably difficult employees should be discussed in detail instead of being handled on the basis of one person's views and personal opinions (Duck, Kirkpatrick, \& Foley 2006; Duck, Foley, \& Kirkpatrick 2006). Labeling someone as difficult oversimplifies the process, because it gives the impression of a stable and permanent, almost an innate, personal characteristic.

Thus, appraisals of difficulty are also related to the social norms of a workplace. In the workplace, people are dependent on each other's expertise. How they see certain behaviors, or the way in which they feel they have permission, or opportunities, to react to those behaviors, is different than in relationships outside the office (Duck, Kirkpatrick \& Foley 2006; Duck, Foley \& Kirkpatrick 2006). Being perceived as problematic by a coworker is only one dimension of the relationship, since, at the same time, the relationship operates also on a professional level. Despite its burdensome features - including the continuous stress caused by feelings of mistrust, fear, and anxiety - it is necessary to maintain the relationship in one way or another in order to work together on shared tasks and achieve organizational goals. 
Occasionally, this may lead to a situation in which one simply feels forced to tolerate the repeated daily negative behavior of a coworker as part of the job.

\section{The Development of Negative Relationships}

In working life, various problems can result from negative relationships. There are few easy answers when dealing with them, and a single reason for the negative development cannot be pinpointed. If the challenges in a relationship could be resolved easily, it would not be a difficult relationship (Hess \& Sneed 2012). In today's workplace, various forms of communication technology are used for interpersonal communication. New tools have diversified communication possibilities in work relationships, and consequently, the tools provide new ways also for negative communication to occur (Vranjes, Baillien, Vandebosch, Erreygers, \& De Witte 2017).

There are numerous explanations for why a relationship in the workplace turns sour. These often include communication behavior perceived as offensive, unprofessional, envious, or overly competitive. The interaction can also become challenging due to unresolved misunderstandings (Morrison \& Nolan 2007). Also distracting occurrences, contradictory expectations, promotion, and deception have been perceived as possible causes for relationship deterioration (Sias et al. 2004). Moreover, the nature of a relationship itself can create particular risks, such as those involved in balancing various relational dimensions. Workplace relationships are primarily professional; therefore, close friendships between coworkers or an intimate relationship between a leader and a follower can create contradictions. For example, although it is sometimes necessary to provide negative feedback to a close friend regarding job performance, doing so can be difficult (Morrison \& Nolan 2007).

Workplace conflicts occur in all organizations; they are inevitable, and they can arise between both individuals and groups. If they are successfully and productively managed, they do not escalate into substantial problems. Conflicts do have constructive potential as they offer the possibility of clarifying goals and expressing opinions as well as listening to different ideas and needs. This way they give rise to, for example, better decision-making. However, conflicts can also have destructive consequences. When unresolved and poorly managed, they can, intentionally or not, escalate into more hurtful behavior directed toward at least one of the participants (e.g., Baillien et al. 2016). 
The poor management of conflicts and other problems in leadership, organizational changes, and constant negative pressure in the workplace can undermine employees' well-being (Robertson \& Cooper 2011). Conflicts and more severe relational problems may not always be caused, either directly or indirectly, by the surrounding working conditions. However, poor workplace conditions will most likely not support the positive development of relationships when people encounter challenges.

One way in which the developmental path of a particular relationship can be charted is by identifying specific turning points along its path. A relational turning point is an episode the participants might remember as having changed the nature of their relationship, changed its development, or altered their overall conception of the relationship (e.g., Baxter \& Bullis 1986). For example, negative turning points in coworker relationships are related to the negative behavior of the participants directed toward each other or toward someone else in the workplace. An impression of a coworker can turn negative as a consequence of perceived inappropriate behavior, false accusations, lying, hiding information, opportunistic behavior, or manipulation directed either at the relational partner or the entire working community. Relational turning points can also be, predictably, related to work duties (Hess, Omdahl, \& Fritz 2006). The leader can perceive the performance of a follower as being inadequate. The follower can also perceive the leader's expectations as being unrealistic within, for example, the given time limit.

A negative workplace relationship does not develop in a void. Maintaining a negative relationship is always connected to a larger network of relationships at work. The actions of third parties could also be identified as having an influence, because they might complain, gossip, or engage in slander about the relational partner. At their best, coworker relationships can be a significant source of emotional support, and they are instrumental in providing that support every day, especially in demanding relational situations. However, dealing with problematic relationships can create tensions if, for example, those struggling with a problematic coworker feel that they do not have the support they need from their trusted coworkers, after all. Moreover, they may not find the advice they receive as applicable or helpful if that advice targets the behavior of the perceived victim instead of the negative behavior of the problematic coworker. 
Often, the coworkers who observe negative relationships as third parties might discuss them with the participants as well as with each other. Having to witness serious and unresolved relationship conflicts affects such coworkers' well-being as well (e.g., Vartia 2001), which further demonstrates the necessity of early supportive action to achieve reconciliation.

\section{Workplace Bullying}

Like any negative relational process, workplace bullying is essentially a communication process (West \& Turner 2019). Communicative acts of bullying are classified as either direct or indirect. Thus, bullying can include very direct and open verbal attacks, threats, obscenities, and constant criticism. Indirect bullying, however, is enacted through hardly noticeable relational acts, such as excluding a person from the working community, teams, or other work groups. Bullying in the workplace may also involve complex manipulation of the target's reputation through gossip and slander.

Furthermore, the ability of the targets of bullying to fulfill their professional duties is likely to come under attack in many ways. For example, a workplace bully may have the ability to control and/or provide the information that the target needs. Withholding the necessary information from the target can significantly complicate that person's ability to perform their duties. During a bullying process, the targets often perceive that their intellectual abilities, trustworthiness, skills as a worker, and ability to contribute to the efforts of the working community are repeatedly questioned through words and deeds, either directly or indirectly (Einarsen, Hoel, Zapf, \& Cooper 2003). Understandably, bullying can cause severe psychological distress to the people involved, including those accused of bullying (Jenkins, Winefield, \& Sarris 2011).

Workplace bullying consists of perceived long-lasting and repeated, negative, and unethical communicative acts that are directed, deliberately or unconsciously, against one or more people in the same working community. Workplace bullying and workplace conflicts definitely overlap, because they have many features in common. Both are communication processes that burden the people in the relationship, and both provoke negative emotions. In workplace bullying, however, the negativity defines the process more unambiguously. Unlike a workplace conflict, bullying does not hold the potential for a positive outcome or a learning experience in the same way that a successful conflict resolution process does. 
The repetition of hurtful behavior over a long period of time is the element that distinguishes bullying from other types of relational problems. A long-term negative relationship can thus be at risk of bullying occurring. The long-term nature of the problems is often explained by the fact that the targets of negative acts find it difficult to defend themselves, and over time, these acts significantly interfere with their job performance and damage the entire working environment (Vartia 2003).

The problems associated with bullying relationships, like those that arise from any problematic relationship, remain unresolved if the participants cannot effectively change the course of their relationship and if timely and appropriate conflict resolution, supervisory support, and intervention remain absent. If negative behavior continues over time, active attempts to resolve the conflicts decrease, and the participants then devote their efforts to coping and protecting themselves from more harm (Zapf \& Gross 2001). This is partly explained by their exhaustion and the long-term reduction of their psychosocial well-being. Even assertive communication or the perceived ability to defend themselves from negative behavior does not protect the targets from the anxiety caused by the overall process (Nielsen, Gjerstad, Jacobsen, \& Einarsen 2017).

At the same time, the participants typically must continue to work together, even closely in some cases. Support and early intervention are, however, necessary to prevent the escalation of bullying-related problems, even if when the target appears to be able to cope with the situation.

In many cases, it is very difficult to obtain clear evidence of an actual intention to hurt someone. This causes practical challenges when responding to complaints regarding actions, such as bullying or harassment. If someone has the experience of being bullied by their workmate, but the workmate denies the accusations, there is no valid evidence of bullying or intention to hurt. The person who has the experience of being the target is easily left without a voice and a way to obtain remedial justice. It seems reasonable to accept that people can hurt others unintentionally. Such unintentional harm may occur because the person has not received adequate feedback about their hurtful behavior. Moreover, their behavior may not in fact deviate from workplace norms, which are sometimes permissive of hostility and incivility and may implicitly legitimize negative behaviors (Neuman \& Baron 2003; Richards \& Daley 2003). Additionally, especially in knowledge work, leaders and peer coworkers often evaluate 
and are critical of each other's performances. Such messages always hold the potential to be perceived as threatening, even when they are delivered in a civil and polite manner (Kinney 2006).

\section{Managing Negative Relationships}

The relational parties and their behavior in conflict situations are often described as connected to their specific, somewhat permanent roles, for example, they can be characterized as either the bully or the target. However, a negative relationship is always reciprocal. The relationship is maintained in daily working situations involving both parties as equally active relational partners.

It has been noted, for example, that bullying relationships consist of interactions that aim to stabilize the problematic relationship. These maintenance behaviors are in fact very similar to those required to maintain the neutral nonvoluntary relationships discussed above. The participants do not passively move away from each other; instead, more or less consciously, they communicate in ways that maintain only the necessary components of their working relationship, with the primary goal of securing their ability to accomplish their tasks. Typically, people who perceive themselves as bullied and those accused of bullying describe a minimal amount of communication, the strategic avoidance of communication, and avoiding difficult topics when communicating (Rainivaara 2009).

Thus, maintaining problematic relationships consists of far more complex forms of communication than do relationships in which people hurt each other repeatedly and actively engage in confrontations. Instead, the participants are aware of situations that may lead to conflicts and consciously avoid volatile conversation topics as well as display of negative emotions. This will further decrease the possibilities of bringing up the relational problems and identifying possible solutions (Kramer \& Tan 2006; Rainivaara 2009). It is therefore essential to increase workers' understanding of the manifestations and the maintenance of problematic relationships in daily workplace communication.

Although the interaction as well as the entire relationship can seem neutral and even passive to outside observers, maintaining it requires strategic actions which can eventually exhaust one's reserves of strength. This will begin to reduce the participants' psychological and physical well-being. However, it can be challenging for peer coworkers or leaders to recognize the strain 
caused by maintaining problematic relationships. Furthermore, the participants' need for both information and emotional support as well as an intervention to overcome the difficult process can remain unnoticed (Rainivaara 2009; Zapf \& Gross 2001). The intervention would allow them to restore their strength and (re)build a safe working environment.

Interaction in a negative relationship can be deliberately minor. If the distancing behaviors and the attempt to stabilize the relationship and to control the perception of its threat are perceived as successful, people might not be motivated to rock the unstable boat by bringing up the problems. The fear of things getting worse often prevents issues like this from being addressed in the workplace (Rainivaara 2009).

However, this does not reduce the need to create opportunities for the participants to discuss the problems and pursue reconciliation. This process calls for open discussion and clear organizational guidelines and channels for dealing with both the perception of being mistreated and the accusations of negative behavior. Moreover, coworkers should be able to report their observations of negative behavior and the possible anxiety caused by such observations.

\section{Prevention and Intervention}

Dealing with problematic relationships in the workplace represents a multifaceted problemsolving challenge for both peer coworkers and leaders. In working life, relational problemsolving competence contains the understanding of the nature of different conflicts. It also includes both the skills and the motivation needed to engage, discuss, reconcile, and monitor the development and improvement of relationships. When discussing the negative encounters and relationships, different accounts and perceptions of the same events should be recognized equally, while accepting that the "final truth" and accurate descriptions of what has happened might not, if ever, be revealed.

In workplaces it is often necessary to define guidelines for suitable workplace behavior and for preventing harassment and bullying. However, if unwanted sexual attention or workplace bullying are defined in only one way in the workplace guidelines, employees may be discouraged to discuss experiences that do not meet those exact criteria. If the guidelines only describe bullying as openly aggressive and easily detectable behavior, much covert bullying behavior may be unrecognized. Thus, the range of the variety of perceptions can be made visible in the work community by purposefully discussing these issues. If a problem occurs, 
either due to a deliberate act or a misunderstanding, the diminished well-being of the participants or even the entire work community, is indisputable proof that the situation requires urgent intervention. It is also important to recognize the variety of reasons for aggressive behavior. For example, job burnout may manifest as aggressive behavior, and this requires more extensive individual support, rehabilitation, and reorganization of the working environment than just conflict management (Weber \& Jaekel-Reinhard 2000).

It is in the employer's interest to encourage the employees to bring up the negative experiences and problems as early as possible, and the relationship quality of workers should also be a theme addressed in regular appraisal discussions. Such discussions are sometimes the only forums in which the leader actually hears about the daily work of their followers. Surveys and follow-up discussions regarding these issues should also be performed on a regular basis, sometimes anonymously.

Offering a variety of forums for bringing up the challenges in interpersonal relationships creates an environment that encourages open discussion about the problems, without fear of the situation getting worse or otherwise leading to unwanted consequences. It is important to note that these means should not be dependent on or controlled solely by the leaders, because leaders can also be participants in negative relationships. Still, sufficient instructions and support for initiating discussions of difficult issues should be available for leaders, because it is inherent in their position that they become involved in negative relationships, in one way or another.

In cases of workplace bullying, the initiative for dealing with the process most often comes from those who see themselves as victims. Reporting bullying is imperative for the intervention to proceed. Training that includes themes such as information and emotional support should be available for leaders and employee safety representatives. Members of the working community can be trained to deal with situations in which a colleague relates their negative experiences to them. For example, expressing disbelief or asking for evidence of maltreatment might severely discourage the perceived target and also threaten the relationship between colleagues.

Workplace conflict mediation is currently applied in a growing number of organizations. In a mediation process, a neutral third party assists coworkers in resolving their ongoing disputes. A successful conflict mediation process is also a learning process. As a result, the parties are 
able to continue their work in a safe environment and better manage any new conflicts that might occur. Successful conflict resolution can contribute to perceived mutual trust in a coworker relationship, thus strengthening the relationship. Moreover, conflicts can be detected earlier. When the conflicting voices are equally heard and different views are expressed, the quality of the resulting decisions can be enhanced. Conflicts can also bring to light the workplace practices and processes that need to be improved. Therefore, workplace conflicts possess the potential for many positive outcomes, and they should not be deliberately avoided. Managing conflicts requires cooperation, establishing a common goal, and encouraging everyone's contribution to achieving it. Ultimately, an appropriate and realistic goal in managing problematic relationships is case-specific. (Haynes, Haynes, Fong, \& Mann 2004). In all cases, the common goal should be a nonhostile and safe working relationship.

\section{Practical Implications}

Negative communication labels the development and maintenance of problematic relationships, whereas positive communication promotes civility, social support, empathy, forgiveness, and reconciliation. In the workplace, preventing the development of negative relationships very much depends on the ways people communicate with their colleagues during their ordinary, everyday encounters. It also depends on the ways organizations discuss their expectations and express their rules regarding ethical, civil, and professional communication (Fritz 2014; 2019). Therefore, the following questions can be used to initiate a discussion of these issues:

- How do we express different opinions and disagreements and manage conflicts?

- How do we give and receive feedback?

- How do we offer and request social support?

Understanding the consequences of negative behavior for both the individuals involved and the entire working community increases the motivation for systematic conflict management and mediation training in organizations. This will help create a workplace communication culture that allows conflicts to surface, understands their positive and productive potential, and offers tools for their management.

\section{What to Consider in the Workplace}

- Expectations and guidelines regarding professional and civil behavior can be discussed in suitable workgroups. 
- Every workplace should have a plan of action or guidelines for preventing harassment and bullying and for intervening in them.

- Support should be available, and sufficient instructions should be prepared for initiating discussions about issues concerning relational challenges that are perceived difficult by leaders and followers.

- Surveys about the experienced quality of working life and conditions should include questions regarding coworker relationship quality, and the theme should also be included in appraisal discussions.

- Training on workplace communication competence should be arranged in the workplace. The training should include themes such as providing and receiving feedback, conflict management, and social support.

References

Baillien, E., Camps J., van der Broeck, A., et al.. 2016. An eye for an eye will make the whole world blind: Conflict escalation into workplace bullying and the role of distributive conflict behavior. Journal of Business Ethics 137(2), 415-429.

Baxter, L. A. \& Bullis, C. 1986. Turning points in developing romantic relationships. Human Communication Research 12(4), 469-493.

Branch, S., Ramsay, S., \& Barker, M. 2007. Managers in the firing line: Contributing factors to workplace bullying by staff - an interview study. Journal of Management \& Organization 13(3), 264-281.

Chiaburu, D. S. \& Harrison, D. A. 2008. Do peers make the place? Conceptual synthesis and meta-analysis of coworker effects on perceptions, attitudes, OCBs, and performance. Journal of Applied Psychology 93(5), 1082-1103.

Duck, S., Foley, M. K. \& Kirkpatrick, D. C. 2006. Uncovering the complex roles behind the "difficult" worker. In J. M. H. Fritz \& B. M. Omdahl (Eds.) Problematic relationships in the workplace. New York: Peter Lang, 3-20.

Duck, S., Kirkpatrick, D. C., \& Foley, M. K. 2006. Difficulty in relating: Some conceptual problems with "problematic relationships" and difficulties with "difficult people." In D. C. Kirkpatrick, S. Duck, \& M. K. Foley (Eds.) Relating difficulty: The process of constructing and managing difficult interaction. Mahwah, NJ: Lawrence Erlbaum, 1-13.

Einarsen, S., Hoel, H., Zapf, D. \& Cooper, C. L. 2003. The concept of bullying at work: The European tradition. In S. Einarsen, H. Hoel, D. Zapf, \& C. L. Cooper (Eds.) Bullying and emotional abuse in the workplace: International perspectives in research and practice. London: Taylor \& Francis, 3-30.

Fritz, J. M. H. 2002. How do I dislike thee? Let me count the ways: Constructing impressions of troublesome others at work. Management Communication Quarterly 15(3), 410-438.

Fritz, J. M. H. 2014. Professional civility: Communicative virtue at work. New York: Peter Lang.

Fritz, J.M.H. 2019. Communicating ethics and bullying. In R. West \& C. S. Beck (Eds.) The Routledge handbook of communication and bullying. New York: Routledge, 22-29. 
Fritz, J. M. H. \& Omdahl, B. L. (Eds.). 2006. Problematic relationships in the workplace. New York: Peter Lang.

Haynes, J. M., Haynes, G. L., Fong, L. S., \& Mann, R. D. 2004. Mediation: Positive conflict management. Albany, NY: State University of New York Press.

Hess, J. A. 2002. Distance regulation in personal relationships: The development of a conceptual model and a test of representational validity. Journal of Social and Personal Relationships 19(5), 663-683.

Hess, J. A. 2003. Maintaining undesired relationships. In D. J. Canary \& M. Dainton (Eds.) Maintaining relationships through communication: Relational, contextual, and cultural variations. Mahwah, NJ: Lawrence Erlbaum, 103-126.

Hess, J. A. 2006. Distancing from problematic coworkers. In J. M. H. Fritz \& B. M. Omdahl (Eds) Problematic relationships in the workplace. New York: Peter Lang, 205-232.

Hess, J. A., Omdahl, B. L. \& Fritz, J. M. H. 2006. Turning points in relationships with disliked coworkers. In J. M. H. Fritz \& B. L. Omdahl (Eds.) Problematic relationships in the workplace. New York: Peter Lang, 89-106.

Hess, J. A. \& Sneed, K. A. 2012. Communication strategies to restore working relations: Comparing relationships that improved with ones that remained problematic. In B. M. Omdahl \& J. M. H. Fritz (Eds.) Problematic relationships in the workplace. Vol. 2. New York: Peter Lang, 233-256.

Jenkins, M. F., Winefield, H., \& Sarris, A. 2011. Consequences of being accused of workplace bullying: An exploratory study. International Journal of Workplace Health Management 4(1), 33-47.

Keashly, L. \& Jagatic, K. 2003. By any other name: American perspectives on workplace bullying. In S. Einarsen, H. Hoel, D. Zapf, \& C. L. Cooper (Eds.) Bullying and emotional abuse in the workplace: International perspectives in research and practice. London: Taylor \& Francis, 31-61.

Kinney, T. A. 2006. Should I stay or should I go now? The role of negative communication and relational maintenance in distress and well-being. In J. M. H. Fritz \& B. M. Omdahl (Eds.) Problematic relationships in the workplace. New York: Peter Lang, 179-201.

Kline, R. \& Lewis, D. 2019. The price of fear: Estimating the financial cost of bullying and harassment to the NHS in England. Public Money and Management 39(3), 166-174. doi:10.1080/09540962.2018.1535044.

Kramer, M. W. \& Hess, J. 2002. Communication rules for the display of emotions in organizational settings. Management Communication Quarterly 16(1), 66-80.

Kramer, M. W. \& Tan, C. L. 2006. Emotion management in dealing with difficult people. In J. M. H. Fritz \& B. L. Omdahl (Eds.). Problematic relationships in the workplace. New York: Peter Lang, 153-178.

Leymann, H. 1996. The content and the development of bullying at work. European Journal of Work and Organizational Psychology 5(2), 165-184. 
Lutgen-Sandvik, P., Tracy, S. J., \& Alberts, J. K. 2007. Burned by bullying in the American workplace: Prevalence, perception, degree and impact. Journal of Management Studies 44(6), 837-862.

Methot, J. R., Melwani, S., \& Rothman, N. B. 2017. The space between us: A socialfunctional emotions view of ambivalent and indifferent workplace relationships. Journal of Management 43(6), 1789-1819.

Morrison, R. L. \& Nolan, T. 2007. Negative relationships in the workplace: A qualitative study. Qualitative Research in Accounting and Management 4(3), 203-221.

Neuman, J. H. \& Baron, R. A. 2003. Social antecedents of bullying. A social interactionist perspective. In S. Einarsen, H. Hoel, D. Zapf, \& C. L. Cooper (Eds.) Bullying and emotional abuse in the workplace: International perspectives in research and practice. London: Taylor \& Francis, 185-202.

Nielsen, M. B, Gjerstad, J., Jacobsen, D. P., \& Einarsen, S. V. 2017. Does ability to defend moderate the association between exposure to bullying and symptoms of anxiety? Frontiers in Psychology 8(1953). doi:10.3389/fpsyg.2017.01953.

Rainivaara, S. 2009. Workplace bullying relationships. In T. A. Kinney \& M. Pörhölä (Eds.) Anti- and pro-social communication. Theories, methods, and applications. New York: Peter Lang, 59-70.

Richards, J. \& Daley, H. 2003. Bullying policy: Development, implementation and monitoring. In S. Einarsen, H. Hoel, D. Zapf, \& C. L. Cooper (Eds.) Bullying and emotional abuse in the workplace: International perspectives in research and practice. London: Taylor \& Francis, 127-144.

Robertson, I. \& Cooper, C. L. 2011. Well-being: Productivity and happiness at work. Basingstoke: Palgrave Macmillan.

Sias, P.M., Heath, R.G., Perry, T., Silva, D., \& Fix, B. 2004. Narratives of workplace friendship deterioration. Journal of Social \& Personal Relationships 21(3), 321-340.

Vartia, M. 2001. Consequences of workplace bullying with respect to the well-being of its targets and the observers of bullying. Scandinavian Journal of Work and Environmental Health 27(1), 63-69.

Vartia, M. 2003. Workplace bullying: A study on the work environment, well-being and health. People and Work Research Reports 56.. Finnish Institute of Occupational Health. Available at: http://urn.fi/URN:ISBN:951-802-526-6

Vranjes, I., Baillien, E., Vandebosch, H., Erreygers, S., \& De Witte, H. 2017. The dark side of working online: Towards a definition and an Emotion Reaction model of workplace cyberbullying. Computers in Human Behavior 69, 324-334. doi:10.1016/j.chb.2016.12.055.

Weber, A. \& Jaekel-Reinhard, A. 2000. Burnout syndrome: A disease of modern societies? Occupational Medicine 50(7), 512-517.

West, R. \& Turner, L. H. 2019. Coming to terms with bullying. A communication perspective. In R. West \& C. S. Beck (Eds.) The Routledge handbook of communication and bullying. New York: Routledge, 3-12. 
Zapf, D. \& Gross, C. 2001. Conflict escalation and coping with workplace bullying: A replication and extension. European Journal of Work and Organizational Psychology 10(4), 497-522. 